\title{
FOLSOMIA CANDIDA (COLLEMBOLA) LOCOMOTOR ACTIVITY PATTERN IS CHANGED BY A NEUROTOXICANT PESTICIDE
}

\author{
Borbála Szabó, Anikó Seres and Gábor Bakonyi \\ Department of Zoology and Animal Ecology, Szent István University \\ H-2100 Gödöllö, Páter K. u. 1., Hungary \\ E-mails:szbori001@gmail.com,bakonyi.gabor@mkk.szie.hu, seres.aniko@mkk.szie.hu
}

Behavioural traits, including locomotor activity, have become relevant parameters in contemporary ecotoxicology. However, insecticide effects on soil animal behaviour has remained a neglected field until now. The Trebon 30 EC is an expansively used pyrethroid insecticide in many countries, which has a broad spectrum of activity. It is recommended against pests of different vegetables, cereals, fruits, and flowers. The effect of this insecticide on the behaviour of collembola Folsomia candida has never been tested. Nevertheless, an effect is likely, because of the neurotoxic nature of the Trebon 30 EC insecticide. This study aimed to determine, (i) whether the Trebon $30 \mathrm{EC}$ insecticide (active ingredient: etofenprox) prevails on the collembola F. candida locomotor activity pattern immediately after insecticide application and (ii) if there is any temporal change in the locomotor activity pattern within one hour of insecticide application. Prompt hyperactivity followed by strongly reduced locomotor activity of F. candida due to Trebon 30 EC application has been demonstrated in this study. Collembola started to run faster even when a tenfold concentration of the recommended field rate was applied. Moreover, this insecticide causes locomotor irregularity in F. candida. Chronic insecticide exposure has a negative impact on all studied locomotor traits of this collembola, resulting in a knockdown effect.

Keywords: Folsomia candida, etofenprox insecticide, locomotor activity, neurotoxicant pesticide.

\section{INTRODUCTION}

Collembola play a key role in agricultural soils (LaRINK 1997). They significantly contribute to vital integrative processes, as decomposition and mineralisation (Verhoef \& BrussaArd 1990, Beare et al. 1992, Coleman et al. 2002). Collembolan populations have an influential position in soil food web networks with strong effects on community structure (Halaj \& Wise 2002, KANEDA \& KANEKo 2008). Consequently, any agricultural impact on collembolan populations, including pesticide application, could have a severe outcome on agroecosystem functioning.

Pyrethrins and pyrethroids are commonly used pesticides to control agricultural and household pests. They quickly penetrate and act on the insects' nervous system, causing hyperactivity (Isman 2006), then paralysis and loss of movement coordination by prolonging the opening of sodium chan- 
nels in nerve cells. This is a relatively quick, so-called knockdown process (Schleier \& Peterson 2011). The knockdown effect has been extensively studied in mosquito control (Liu 2015, LuKwa et al. 2012), the housefly (SAwICKI 1962), stored-product beetles (Toews et al. 2003), locusts (CLEments \& MaY 1977) and the bloodsucking bug Triatoma infestans (Alzogaray \& Zerba 1997). Knockdown resistance can arise after continuous pesticide application. That is why the knockdown effect of the same pesticide may be different in various populations of same species. This problem is especially relevant in mosquito control, where pyrethroids are applied for a long time (Lukwa et al. 2012). The knockdown effect is a rapid process, often acting in minutes, sometimes in a few hours. A mosquito is knocked down if it is not able to stand or fly in a coordinated manner after 60 minutes of the insecticide application (WHO 2013). The knockdown outcome is rarely lethal, and recovery occurs in most cases (Alzogaray \& Zerba 1997). However, according to Benoit (1986) and RAJASHEKAR and ShivanANDAPpa (2017), knockdown usually precedes death.

The Trebon 30 EC (Mitsui Chemicals, Inc.) is an expansively used pyrethroid insecticide in several countries, mainly in Asia. The active ingredient is etofenprox (2-(4-ethoxyphenyl)-2-methylpropyl-3-phenoxybenzyl-ether). This insecticide contains etofenprox in a concentration of $287.5 \mathrm{~g} / 1(30 \% \mathrm{~m} / \mathrm{m})$. Etofenprox acts as contact poison through consumption, and its knockdown effect is also known (Brancato et al. 2017). This insecticide has 49.1-100 and 27.5 days of half-life under anaerobic and aerobic conditions $\left(\right.$ at $22 \mathrm{C}^{\circ}$ ), respectively in an agricultural soil (VAsquez et al. 2011). Absorption of the etofenprox onto soil particles is strong (EU 2013). Etofenprox is a broad-spectrum pyrethroid. It has low toxicity to mammals (Үоснімото et al. 1989), but it is very toxic to aquatic animals (ECHA 2012) such as rainbow trout and bluegill sunfish ( $\mathrm{LC}_{50} 0.032 \mathrm{mg} / \mathrm{l}, 96 \mathrm{~h}$, for both species), as well as for Daphnia magna $\left(\mathrm{LC}_{50} 0.0027 \mathrm{mg} / \mathrm{l}, 48 \mathrm{~h}\right.$ ) (CERTIS 2015). It is recommended against pests affecting different vegetables, cereals, fruits, and flowers. In China, etofenprox is one of the most important pesticides for controlling the rice planthopper, the cabbage caterpillar, and the cotton bollworm (ZHANG et al. 2013). This active ingredient is also used in the USA (Boina \& Bloomquist 2015), Iran (VAtanDoost et al. 2004) and West Africa (MARTin et al. 2002). However, side effects of the etofenprox on soil arthropod behaviour are not known.

In consequence of its neurotoxic nature, the etofenprox effect was found on the behaviour of the earwig, Doru luteipes (CAmpos et al. 2011), honey bee, Apis mellifera (Матsumoto 2013), bean bug, Riptortus pedestris (MaharJan \& Jung 2015), and Aedes aegypti mosquito (Agramonte et al. 2017). As the etofenprox containing insecticides are applied by spraying on fields, collembolan exposure to pesticides is quite likely. Moreover, side effects of etofenprox 
(being a neurotoxic agent) on the behaviour of collembolan is also probable; however, such data has been unavailable until now.

Folsomia candida is a representative of soil mesofauna in laboratory studies. A standard avoidance test of polluted soils with this species is available (ISO 2011) and has been used in several studies. The jumping ability of $F$. candida significantly decreased with enhancement of soil $\mathrm{Cu}$ and $\mathrm{Ni}$ contamination (KIM \& AN 2014). A low rate application (one-quarter and one-eighth of the recommended field application rate in Denmark) of the insecticide Dimethoate $400 \mathrm{~g} / \mathrm{l}$, EC (active ingredient: dimethoate) enhanced the turning rate and average velocity of $F$. candida during the 36 hours of the study (Sørensen et al. 1995). The orientation of F. candida in the direction of the food source (AUCLERC et al. 2010) was also proved.

The side effects of the extensively used insecticide Trebon 30 EC on soil fauna are hardly known. We found (SzAвó \& BAкоNYI 2017) that F. candida laid smaller eggs in a concentration-dependent manner if Trebon $10 \mathrm{~F}$ (active ingredient: etofenprox) was applied. That is why this study aims to determine, whether (i) the Trebon 30 EC insecticide (active ingredient: etofenprox) knockdown effect prevails on the collembola F. candida locomotor activity pattern immediately after insecticide application, and (ii) if there is a considerable change in locomotor activity components after etofenprox treatment in different concentrations. Alteration of the locomotor activity pattern within one hour of insecticide application was also determined to check temporary changes.

\section{MATERIAL AND METHODS}

Folsomia candida (Willem 1902) is a cosmopolitan soil animal species, which exists almost all over the globe, including North America and Europe. It prefers soils with a high level of organic matter, but is common in various forest and agricultural soils as well. It is a focal laboratory animal and widespread object of different ecotoxicological tests. More information and a detailed description of $F$. candida biology and ecotoxicology can be found in Fountain and Hopkin (2005), Hopkin (1997), and Krogh (2009).

Collembola used in this study was obtained from our stock populations at Szent István University, Department of Zoology and Animal Ecology. This species has been reared continuously in the laboratory for the past 25 years. F. candida reared in our laboratory belongs to the lineage $B$, according to the categories of Tully et al. (2006). Collembolas are kept under standard conditions in Petri dishes with a diameter of $9 \mathrm{~cm}$, according to the method of Gото (1960). The bottom of the Petri dish is filled with plaster of Paris mixed with activated charcoal (10:1 volume ratio). The temperature of the incubation cabinet is $20 \pm 0.2^{\circ} \mathrm{C}$, with $\sim 100 \%$ humidity. The animals are in total darkness. Petri dishes are watered as needed to maintain consistent humidity. The collembolas are fed with dry baker's yeast once per week, ad libitum.

The experiment was performed in $9 \mathrm{~cm}$ diameter Petri dishes filled with a $0.5 \mathrm{~cm}$ layer of plaster of Paris and powdered graphite $(9: 1)$ mixture. It was kept moist during the experiment to allow for $100 \%$ moisture content in the dish. Three concentrations were 
applied as follows: control, 1.3 and $13 \mathrm{ml}$ Trebon $30 \mathrm{EC} / 1.1 .3 \mathrm{ml}$ Trebon $30 \mathrm{EC} / \mathrm{l}$ is a recommended field concentration of this insecticide against pests in potatoes. After the Trebon 30 EC application, Petri dishes were aerated for one hour to allow the naphthalene, one of the components of this insecticide, to evaporate. According to our previous experiments, one hour is enough for naphthalene evaporation under our experimental circumstances. $F$. candida young adults $(2.22 \pm 0.17 \mathrm{~mm})$ were used in the experiment.

Collembolan behaviour was studied with the aid of video records. One plastic ring (15 $\mathrm{mm}$ in diameter) was placed in the middle of the Petri dish and one F. candida individual was put into it. Two series of experiments were performed. In the first experiment, individuals were introduced into the plastic ring immediately after naphthalene evaporation and video record was started prompt (3 treatments, 12 replicate per treatment). With the aid of this experimental set-up, we can answer the following question: which method alters F. candida activity when it comes in contact with the pesticide immediately after spraying? In the second experiment, collembola were left for one hour in the plastic ring after naphthalene evaporation, then the video recording started (3 treatments, 4 replicate per treatment). Some collembola died during this hour, but others survived. With the aid of this experimental set-up, we can answer the following question: compared to the control, is there any change in the activity of the collembola which survived?

The covered Petri dishes were placed under an STM9-TRI binocular microscope. The illumination was homogeneous with the aid of a fiber-optic light source placed around the objective lens. The video record was performed with a 3.2 MP MicroQ-W (widefield) PRO camera and the processing speed was 12 frames s$^{-1}$. Records were analysed with the BORIS v. 3.60 software (FRIARD \& GAMBA 2016). The movement of each collembola within the arena was recorded for two minutes. The total times of locomotion activity and path length, i.e. total walked distance, time spent standing in two minutes and average velocity during locomotion activity were determined. Moreover, path lengths of the locomotion activity were also assessed. The total video length ( 2 minutes) was divided into 0.5 -second parts (PL0.5). The distance moved during all 0.5 seconds was also determined. Distribution of these distances was plotted in histograms.

Statistical analyses were performed with the PAST statistical software package (HAMMER et al. 2001). The Trebon 30 EC effect was determined by the generalized linear model (GLM). Uniformity of path length distribution was checked by the Mann-Whitney test. The accepted level of significance was $\mathrm{p}<0.05$ in all cases.

\section{RESULTS AND DISCUSSION}

Immediately after insecticide contact (in the first two minutes after putting collembolans into the contaminated Petri dish), hyperactivity of $F$. candida was detected. Applied concentrations of the Trebon 30 EC were not related to locomotion activity and time spent standing (Table 1). However, longer path length and average velocity during locomotion activity were observed at higher insecticide concentration (Table 1). A positive relationship between path length and average velocity during locomotion activity was observed $(y=0.0087 x ; r=0.95 ; p<0.001)$ (Fig. 1). This relationship was independent of the treatments. We found in other unpublished experiments that the longer path length, the quicker the collembola F. candida run. Similar results have 
Table 1. Relationship of the measured locomotor activity traits of $F$. candida and Trebon 30 EC concentrations in the first two minutes after putting collembolans into the contaminated Petri dish. NS: non significant. Concentration unit is $\mathrm{ml}$ Trebon $30 \mathrm{EC} / \mathrm{l}$.

\begin{tabular}{lcc}
\hline Behaviour & $\begin{array}{c}\text { Relationship with } \\
\text { pesticide concentration }\end{array}$ & Significance (p) \\
\hline Locomotion activity (LA) (sec) & $\mathrm{y}=0.39 \mathrm{x}+104.4$ & $0.57(\mathrm{NS})$ \\
Standing (S) (sec) & $\mathrm{y}=-0.39 \mathrm{x}+15.6$ & $0.57(\mathrm{NS})$ \\
Path length (PL) (mm) & $\mathrm{y}=6.94 \mathrm{x}+224.0$ & 0.024 \\
Velocity (V) (mm/sec) & $\mathrm{y}=0.06 \mathrm{x}+2.1$ & 0.007 \\
\hline
\end{tabular}

been found in studies with carabid beetles Pterostichus cupreus (Jensen 1997) and Scarites quadriceps (Prasifka et al. 2008).

Hyperactivity was detected when three different strains of the bug Triatoma infestans were treated with deltamethrin, lambda-cyhalothrin and tetramethrin (SFARA et al. 2006). Rapid horizontal movement of the agricultural pest stink bug Halyomorpha halys was observed immediately after exposure to nine pyrethroid insecticides by LeE et al. (2013). Dimethoate, an organophosphate compound, induced hyperactivity at sublethal doses in the woodlice, Porcellio scaber (BAyley \& BAATRUP 1996). However, the predatory bug, Supputius cincticeps showed hypoactivity after chlorantraniliprole application (De CAstro et al. 2013). In our experiment, the insecticide Trebon 30 EC immediately enhanced the locomotor velocity and path length of $F$. candida, which are signs of hyperactivity. This reaction and lack of the knockdown effect im-

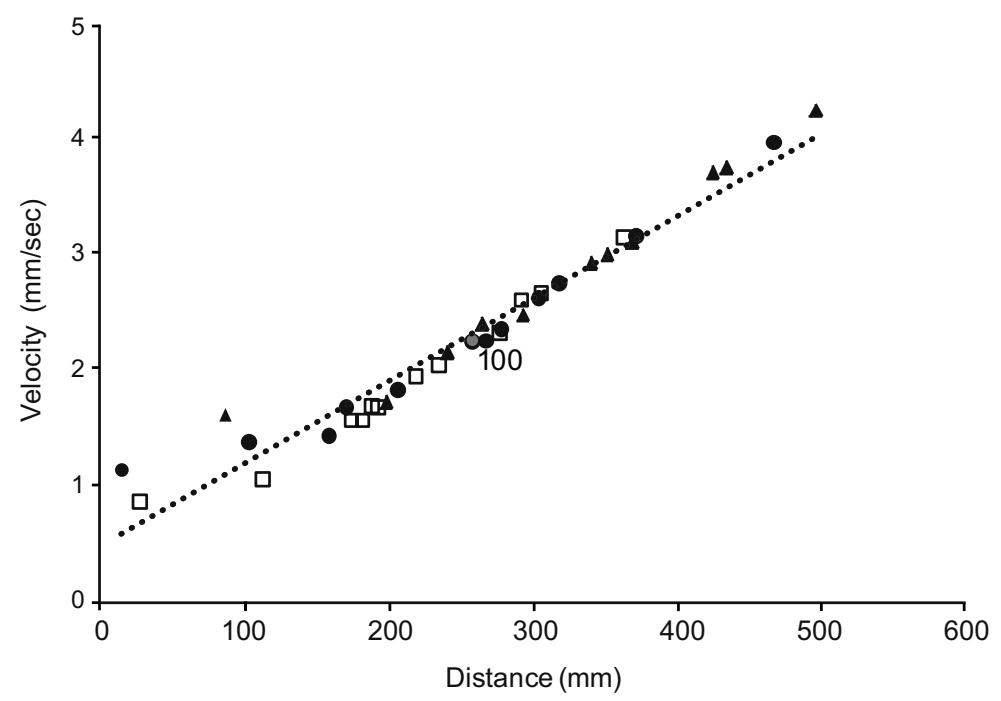

Fig. 1. Relationship between walked distance and velocity of $F$. candida. Open square: control, filled circle: treatment $1.3 \mathrm{ml}$ Trebon $30 \mathrm{EC} / \mathrm{l}$, filled triangle: treatment $13 \mathrm{ml}$ Trebon $30 \mathrm{EC} / \mathrm{l}$ 
Table 2. Skewness and kurtosis of the path lengths in 0.5 second during the locomotion activity of $F$. candida in the relation of Trebon 30 EC concentration.

\begin{tabular}{lccc}
\hline Trebon 30 EC $(\mathrm{ml} / \mathrm{l})$ & 0 & 1.3 & 13 \\
\hline Skewness & 1.615 & 1.233 & 0.88 \\
Kurtosis & 1.398 & -0.032 & -0.849 \\
\hline
\end{tabular}

mediately after insecticide application may be an escape reaction, which helps collembola survive on the field.

PL0.5 distribution changed with insecticide concentration (Fig. 2). In the control treatment, the frequency of short distances dominated, i.e., collembola usually moved short distances. Higher concentrations enhanced the frequency of longer path lengths. The proportion of the $0-5 \mathrm{~mm}$ long path were 35.7, 26.9 and 21.1 percent of the total in the control, 1.3 and $13 \mathrm{ml}$ Trebon $30 \mathrm{EC} / 1$ treatment, respectively. The PL0.5 distribution in the control and $13 \mathrm{ml}$ Trebon 30 $E C / 1$ treatments differed significantly $(p=0.038)$. Therefore, the distribution mean was altered. Skewness values are positive in all cases, showing that data are skewed right. However, skewness became lower as the concentration was raised (Table 2). Kurtosis values decreased as the concentration increased (Table 2). This figure indicates that outliers, e.g., extreme path lengths, become more frequent with the increase of the concentration (WestFall 2014). Lower skewness and kurtosis values parallel with enhanced concentration may be a sign of the locomotor irregularity due to insecticide. Pyrethroid insecticides cause locomotor irregularity in rats (WEINER et al. 2009), but this occurrence is still unexplored.

The length of the initial hyperactivity is different depending on the species tested, mode of the action of pesticide, and applied concentrations. No comparative study is available about the most decisive factors, which determine the hyperactivity length of the insects. Concentration proved to be a significant feature when carabids, Platynus assimilis (Tooming et al. 2014, 2017) and Scarites quadriceps (PrasifKa et al. 2008) were tested.

Table 3. Relationship of the measured locomotor activity traits of $F$. candida and Trebon 30 EC concentrations when collembolans spent one hour in the contaminated Petri dish.

Concentration unit is $\mathrm{ml}$ Trebon $30 \mathrm{EC} / \mathrm{l}$.

\begin{tabular}{lcc}
\hline Behavior & $\begin{array}{c}\text { Relationship with } \\
\text { pesticide concentration }\end{array}$ & Significance (p) \\
\hline Locomotion activity (LA) (sec) & $\mathrm{y}=-7.1 \mathrm{x}+114.6$ & 0.000 \\
Standing (S) (sec) & $\mathrm{y}=7.1 \mathrm{x}+5.3$ & 0.000 \\
Path length (PL) (mm) & $\mathrm{y}=-19.1 \mathrm{x}+261.9$ & 0.000 \\
Velocity (V) (mm/sec) & $\mathrm{y}=-0.13 \mathrm{x}+2.3$ & 0.000 \\
\hline
\end{tabular}



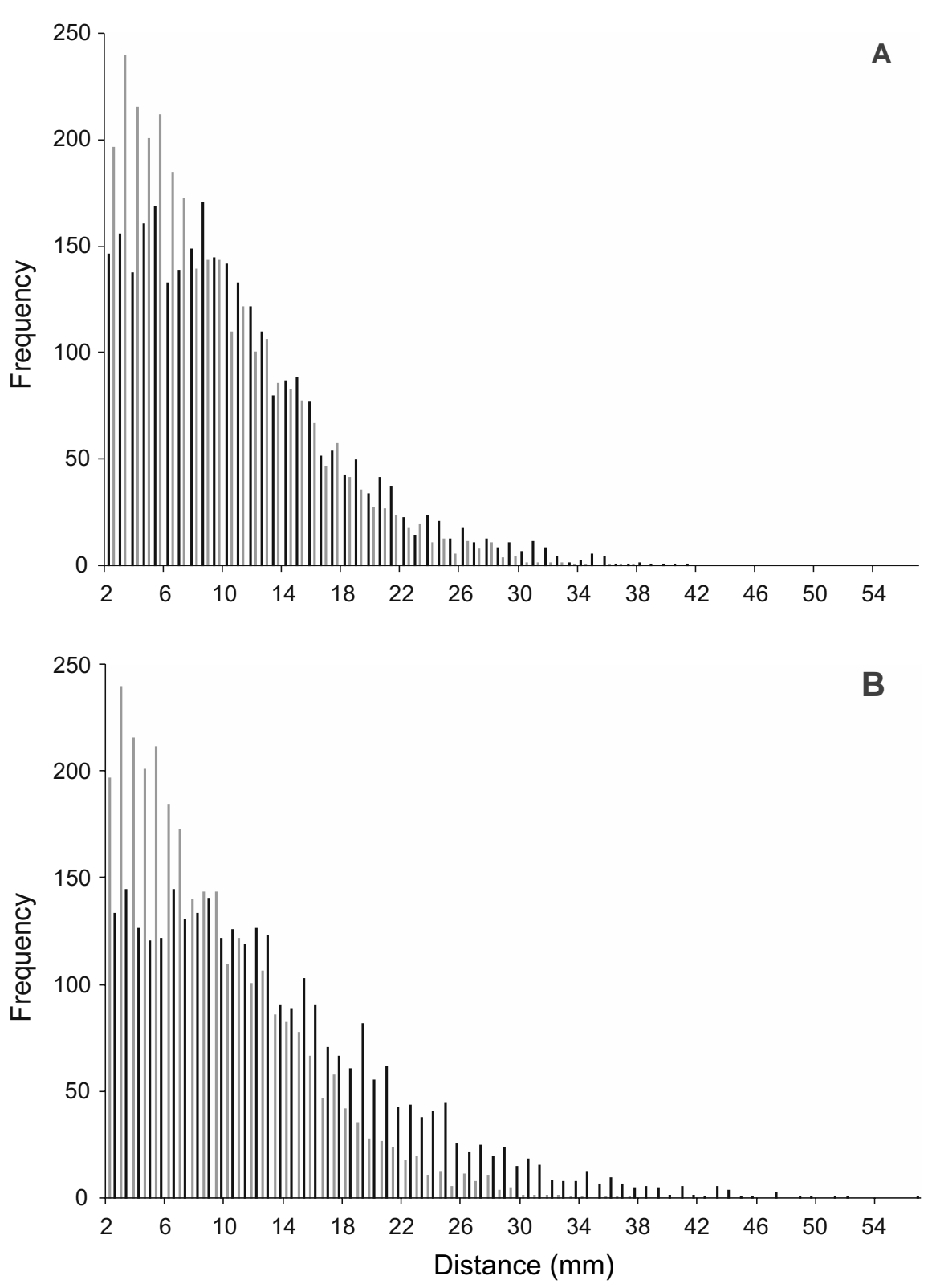

Fig. 2. Histogram of the path lengths in 0.5 second during the locomotion activity of $F$. candida. Histograms are created with $5-\mathrm{mm}$ path length distance class-interval grouping. Frequency shows the number of times each class-interval occurs. A: control (grey) and 1.3 $\mathrm{ml}$ Trebon $30 \mathrm{EC} / \mathrm{l}$ (black), B: control (grey) and $13 \mathrm{ml}$ Trebon $30 \mathrm{EC} / \mathrm{l}$ (black). The number of observations was 2989, 2878 and 3078 for the control, $1.3 \mathrm{ml}$ Trebon $30 \mathrm{EC} / 1$ and, $13 \mathrm{ml}$ Trebon 30 treatment, respectively 
Pesticide application can have opposite effects in insect locomotor behaviour during the time-course (BeNoIt 1986). This was the case in our study, where remarkably different results were found if the F. candida remained in contact with the insecticide for one hour before video recording. In this case, all parameters (locomotion activity, time spent standing, path length, average velocity during locomotion activity) were significantly related to the concentration increase (Table 3). Nonetheless, time spent standing has a positive, but all locomotion activity, path length and average velocity during locomotion activity have a negative correlation with the insecticide concentration. All these results unequivocally show that one hour of insecticide exposure has a knockdown effect on all studied locomotor traits of the F. candida. Etofenprox application to Anopheles gambiae mosquito females resulted in a one hundred percent knockdown effect from 30-55 minutes, depending on the population location (LuKwa et al. 2012). This data is compatible with our results, suggesting a similar mode of action of etofenprox on F. candida and A. gambiae.

Detection of the knockdown effect (Schleier \& Peterson 2011) in any experiment depends on several factors, such as, e.g., insect species, insecticide category, the application method and rate, and observation time. Toews et al. (2003) tested the knockdown effect of the insecticide spinosad on eight species of stored-product beetles and found significant differences among the species. Similarly, Chen et al. (1985) found differences in the effects of 10 pyrethroids, tested on the diamondback moth Plutella xylostella. Rachiplusia $n u$, a soybean pest moth, showed distinct knockdown behaviour on four cyanopyrethroids insecticides and permethrin (Russo 2012). Moreover, permethrin was more toxic if it was applied topically, compared to the situation where larvae were exposed to pyrethroid film on filter paper. The extent of the Fastac 50 EC (active ingredient: alpha-cypermethrin) insecticide knockdown effect on the predatory carabid beetle showed positive concentration dependence, being most effective at the highest alpha-cypermethrin concentration (ToomING et al. 2014).

Prompt hyperactivity followed by reduced locomotor activity of $F$. candida due to Trebon 30 EC application has been demonstrated in this study. Coinciding with our results, LAVTižAR et al. (2016) found a quick avoidance reaction of $F$. candida to the insecticide chlorantraniliprole, which is a ryanodine receptor (calcium-channel) agonist. No hyperactivity was detected if dimethoate, an organophosphate insecticide, was applied in a laboratory experiment. However, dimethoate reduced F. candida velocity and shortened path length during the 36 hours of the study (SørEnsen et al. 1995). In another study, this collembola species was not able to avoid dimethoate-contaminated soil. The reason was probably that dimethoate inhibits acetylcholinesterase activity (Pereira et al. 2013). All these pieces of evidence suggest the high 
diversity of $F$. candida locomotor activity responses to different kind of pesticides and their active ingredients.

Direct, short-term and long-term effects of any insecticide may be considerably different (Fitches \& Gatehouse 1998, Jansen \& Gomez 2014). Benoit (1986) presented a generalized sequence of symptoms of how pyrethroids influence the locomotor activity of the croachcroach Periplaneta americana. It is verified that hyperactivity (excitation phase) is followed by incoordination and then a knockdown (tetanisation) stage. This sequence of symptoms is demonstrated in the present study as well. The time window is an important point. We found in this study that Trebon $30 \mathrm{EC}$ application provokes instant hyperactivity in F. candida. This reaction may help the collembola to escape from further insecticide contact for at least a few minutes. The maximum walking speed of $F$. candida was $0.97 \mathrm{~mm} / \mathrm{sec}$ in a laboratory experiment (SørENsen et al. 1995) and $4.3 \mathrm{~mm} / \mathrm{sec}$ in our study. With this walking speed, the first few minutes after insecticide spraying would be enough to find pore space in the soil, which is a safe place from insecticide droplets. However, in order to test this hypothesis, the repellent or attractant effect of Trebon 30 EC on F. candida should be tested.

The effects of the formulated pesticide and its active ingredient may substantially differ, as was demonstrated in the case of the glyphosate herbicide. It was found that the formulating adjuvant polyethoxylated tallowamine (POEA) is much more toxic to the water flea Daphnia magna than the formulated pesticide Roundup (SzÉKÁcs et al. 2014). Tooming et al. (2014) found that locomotor activity of the carabid Platynus assimilis changed at 75000 -fold lower alpha-cypermethrin concentration than the recommended maximum field concentration. However, Tooming et al. (2014) tested the insecticide Fastac 50EC, its active ingredient alpha-cypermethrin. It is not clear whether the active ingredient or some formulating adjuvant of the insecticide used in the experiment provoked the observed effect. Possible different effects of the formulated pesticide and its active ingredients has been an open question in F. candida locomotor activity studies until now.

Acknowledgements - Supported by the ÚNKP-17-3-IV New National Excellence Program of the Ministry of Human Capacities. We would like to thank two anonymous reviewers for their constructive comments that greatly improved the manuscript. We thank Michelle Suzanne Vitro for polishing of the English. 


\section{REFERENCES}

Agramonte, N. M., Bloomquist, J. R. \& Bernier, U. R. (2017): Pyrethroid resistance alters the blood-feeding behaviour in Puerto Rican Aedes aegypti mosquitoes exposed to treated fabric. - PLoS Neglected Tropical Diseases 11(9): e0005954. https:// doi.org/10.1371/journal.pntd.0005954

Alzogaray, R. A. \& Zerba, E. N. (1997): Incoordination, paralysis and recovery after pyrethroid treatment on nymphs III of Triatoma infestans (Hemiptera: Reduviidae). - Memórias do Instituto Oswaldo Cruz 92: 431-435. https://doi.org/10.1590/S007402761997000300023

Auclerc, A., Libourel, P. A., Salmon, S., Bels, V. \& Ponge, J. F. (2010): Assessment of movement patterns in Folsomia candida (Hexapoda: Collembola) in the presence of food.Soil Biology and Biochemistry 42: 657-659. https://doi.org/10.1016/j.soilbio.2009.12.012

Bayley, M. \& BAatrup, E. (1996): Pesticide uptake and locomotor behaviour in the woodlouse: An experimental study employing video tracking and ${ }^{14} \mathrm{C}$-labelling. - Ecotoxicology 5: 35-45. https://doi.org/10.1007/BF00116322

Beare, M. H., Parmelee, R. W., Hendrix, P. F., Cheng, W., Coleman, D. C. \& Crossley, D. A. (1992): Microbial and faunal interactions and effects on litter nitrogen and decomposition in agroecosystems. - Ecological Monographs 62: 569-591. https:// doi.org/10.2307/2937317

Benoit, M., Bruneau, P. \& Meinard, C. (1986): Comparative activity of tralomethrin and deltamethrin on Periplaneta americana. - Pesticide Biochemistry and Physiology 26: 284-291. https://doi.org/10.1016/0048-3575(86)90070-2

Boina, D. R. \& Bloomquist, J. R. (2015): Chemical control of the Asian citrus psyllid and of huanglongbing disease in citrus. - Pest Management Science 71: 808-823. https:// doi.org/10.1002/ps.3957

Brancato, A., Brocca, D., De Lentdecker, C., Erdos, Z., Ferreira, L., Greco, L., Jarrah, S., Kardassi, D., Leuschner, R., Lythgo, C., Medina, P., Miron, I., Molnar, T., Nougadere, A., Pedersen, R., Reich, H., Sacchi, A., Santos, M., Stanek, A., Sturma, J., Tarazona, J., Theobald, A., Vagenende, B., Verani, A. \& Villamar-Bouza, L. (2017): Reasoned opinion on the review of the existing maximum residue levels for etofenprox according to Article 12 of Regulation (EC) No 396/2005. - EFSA Journal 15: 4964, $57 \mathrm{pp}$.

Campos, M. R., Picanço, M. C., Martins, J. C., Tomaz, A. C. \& Guedes, R. N. C. (2011): Insecticide selectivity and behavioural response of the earwig Doru luteipes. - Crop Protection 30: 1535-1540. https://doi.org/10.1016/j.cropro.2011.08.013

CERTIS (2015): Trebon 30 EC, Safety data sheet. http://www.certiseurope.co.uk/products/ insecticides/detail/article/trebon-30-ec-1.html (downloaded on 25.03.2018)

Chen, J. S., LeE, C. J., YAo, M. G. \& Sun, C. N. (1985): Effect of pyrethroids on knockdown and lack of coordination responses of susceptible and resistant diamondback moth (Lepidoptera: Plutellidae). - Journal of Economic Entomology 78: 1198-1202. https:// doi.org/10.1093/jee/78.6.1198

Clements, A. N. \& May, T. E. (1977): The actions of pyrethroids upon the peripheral nervous system and associated organs in the locust. - Pest Management Science 8: 661-680. https://doi.org/10.1002/ps.2780080611

Coleman, D., Fu, S., Hendrix, P. \& Crossley, D. (2002): Soil foodwebs in agroecosystems: impacts of herbivory and tillage management. - European Journal of Soil Biology 38: 21-28. https://doi.org/10.1016/S1164-5563(01)01118-9 
De Castro, A. A., Corrêa, A. S., Legaspi, J. C., Guedes, R. N. C., Serrão, J. E. \& Zanuncio, J. C. (2013): Survival and behaviour of the insecticide-exposed predators Podisus nigrispinus and Supputius cincticeps (Heteroptera: Pentatomidae). - Chemosphere 93: 1043-1050. https://doi.org/10.1016/j.chemosphere.2013.05.075

ECHA (2012): Opinion proposing harmonised classification and labelling at EU level of Etofenprox. - Committee for Risk Assessment, RAC, Helsinki, 139 pp.

EU (2013): Regulation (EU) $n^{\circ} 528 / 2012$ concerning the making available on the market and use of biocidal products. Evaluation of active substances. Etofenprox (PT 18). - Austria, 106 pp.

Fitches, E. \& Gatehouse, J. A. (1998): A comparison of the short and long-term effects of insecticidal lectins on the activities of soluble and brush border enzymes of tomato moth larvae (Lacanobia oleracea). - Journal of Insect Physiology 44: 1213-1224. https:// doi.org/10.1016/S0022-1910(98)00090-0

Fountain, M. T. \& Hopkin, S. P. (2005): Folsomia candida (Collembola): a "standard" soil arthropod. - Annual Review of Entomology 50: 201-222. https:// doi.org/10.1146/annurev.ento.50.071803.130331

FriARD, O. \& GAMBA, M. (2016): BORIS: a free, versatile open-source event-logging software for video/audio coding and live observations. - Methods of Ecology and Evolution 7: 1325-1330. https://doi.org/10.1111/2041-210X.12584

Gото, H. E. (1960): Simple techniques for rearing of Collembola and a note on the use of fungistatic substances in the cultures. - Entomologist's Monthly Magazine 96: 138-140.

Hammer, Ø., Harper, D. A. T. \& Ryan, P. D. (2001): PAST: Paleontological statistics software package for education and data analysis. - Palaeontologia Electronica 4: 9 pp. http://palaeo-electronica.org/2001_1/past/issue1_01.htm

HalaJ, J. \& Wise, D. H. (2002): Impact of a detrital subsidy on trophic cascades in a terrestrial grazing food web. - Ecology 83: 3141-3151. https://doi.org/10.1890/00129658(2002)083[3141:IOADSO]2.0.CO;2

Hоркіn, S. P. (1997): Biology of the springtails:(Insecta: Collembola). - Oxford University Press, Oxford, $330 \mathrm{pp}$.

IsmAN, M. B. (2006): Botanical insecticides, deterrents, and repellents in modern agriculture and an increasingly regulated world. - Annual Review of Entomology 51: 45-66. https:// doi.org/10.1146/annurev.ento.51.110104.151146

ISO (2011): Soil quality - Avoidance test for determining the quality of soils and effects of chemicals on behaviour - Part 2: Test with collembolas (Folsomia candida). ISO 17512-2:2011 standard. - International Organization for Standardization, Geneva, Switzerland, 13 pp.

Jansen, J. P. \& Gomez, G. S. M. Y. (2014): A large field trial to assess the short-term and long-term effects of 5 insecticides used to control the pollen beetle on parasitic hymenoptera in oilseed rape. - IOBC-WPRS Bulletin 103: 9-16.

Jensen, C. S., GARsdal, L. \& BAatrup, E. (1997): Acetylcholinesterase inhibition and altered locomotor behaviour in the carabid beetle Pterostichus cupreus. A linkage between biomarkers at two levels of biological complexity. - Environmental Toxicology and Chemistry 16: 1727-1732. https://doi.org/10.1002/etc.5620160822

Kaneda, S. \& Kaneко, N. (2008): Collembolans feeding on soil affect carbon and nitrogen mineralization by their influence on microbial and nematode activities. - Biology and Fertility of Soils 44: 435-442. https://doi.org/10.1007/s00374-007-0222-x

KIM, S. W. \& AN, Y. J. (2014): Jumping behaviour of the springtail Folsomia candida as a novel soil quality indicator in metal-contaminated soils. - Ecological Indicators 38: 67-71. https://doi.org/10.1016/j.ecolind.2013.10.033 
Krogh, P. H. (2009): Toxicity testing with the collembolans Folsomia fimetaria and Folsomia candida and the results of a ringtest. - Danish Environmental Protection Agency, Copenhagen, $44 \mathrm{pp}$.

LARINK, O. (1997): Springtails and mites: Important knots in the food web of soils. Pp. 225-264. In.: BencKiser, G. (ed.): Fauna in soil ecosystems: recycling processes, nutrient fluxes, and agricultural production. - M. Decker, Inc., New York, 414 pp.

Lavtižar, V., Berggren, K., Trebše, P., KraAK, M. H., Verweij, R. A. \& van Gestel, C. A. M. (2016): Comparative ecotoxicity of chlorantraniliprole to non-target soil invertebrates. - Chemosphere 159: 473-479. https://doi.org/10.1016/j.chemosphere.2016.06.036

LeE, D. H., Wright, S. E. \& LesKey, T. C. (2013): Impact of insecticide residue exposure on the invasive pest, Halyomorpha halys (Hemiptera: Pentatomidae): analysis of adult mobility. - Journal of Economic Entomology 106: 150-158. https://doi.org/10.1603/EC12265

LiU, N. (2015): Insecticide resistance in mosquitoes: impact, mechanisms, and research directions. - Annual Review of Entomology 60: 537-559. https://doi.org/10.1146/annurevento-010814-020828

Lukwa, N., Sande, S., Munosiyei, P. \& Zimba, M. (2012): Insecticide susceptibility tests conducted in Kamhororo, Masakadza and Chilonga villages in Zimbabwe during the 2011 malaria period. - Journal of Entomological and Acarological Research 44: 19. https:// doi.org/10.4081/jear.2012.e19

MaharJan, R. \& Jung, C. (2015): Insecticide-mediated behavioural avoidance by bean bug, Riptortus pedestris (Heteroptera: Alydidae). - Entomological Research 45: 184-192. https://doi.org/10.1111/1748-5967.12113

Martin, T., Chandre, F., Ochou, O. G., Vaissayre, M. \& Fournier, D. (2002): Pyrethroid resistance mechanisms in the cotton bollworm Helicoverpa armigera (Lepidoptera: Noctuidae) from West Africa. - Pesticide Biochemistry and Physiology 74: 17-26. https:// doi.org/10.1016/S0048-3575(02)00117-7

матsumoто, T. (2013): Reduction in homing flights in the honey bee Apis mellifera after a sublethal dose of neonicotinoid insecticides. - Bulletin of Insectology 66: 1-9.

Pereira, C. M., Novais, S. C., Soares, A. M. \& Amorim, M. J. (2013): Dimethoate affects cholinesterases in Folsomia candida and their locomotion-False-negative results of an avoidance behaviour test. - Science of the Total Environment 443: 821-827. https:// doi.org/10.1016/j.scitotenv.2012.11.044

Prasifka, J. R., Lopez, M. D., Hellmich, R. L. \& Prasifka, P. L. (2008): Effects of insecticide exposure on movement and population size estimates of predatory ground beetles (Coleoptera: Carabidae). - Pest Management Science 64: 30-36. https:// doi.org/10.1002/ps.1460

Rajashekar, Y. \& ShivanAndappa, T. (2017): Mode of action of the natural insecticide, decaleside involves sodium pump inhibition. - PloSOne 12(1): e0170836. https://doi. org/10.1371/journal.pone.0170836

Russo, R., Gamundi, J. C. \& Alzogaray, R. A. (2012): Evaluation of pyrethroids toxicity in a laboratory strain and a field population of Rachiplusia nu (Lepidoptera: Noctuidae) using two bioassay techniques. - Revista de la Sociedad Entomológica Argentina 71: 115-123.

SAwicki, R. M. (1962): Insecticidal activity of pyrethrum extract and its four insecticidal constituents against house flies. III.-Knock-down and recovery of flies treated with pyrethrum extract with and without piperonyl butoxide. - Journal of the Science of Food and Agriculture 13: 283-292. https://doi.org/10.1002/jsfa.2740130409 
Schleier III, J. J. \& Peterson, R. K. (2011): Pyrethrins and pyrethroid insecticides. Pp. 94131. In: Lopez, O. \& Fernández-Bolanos, J. G. (eds): Green trends in insect control. - Royal Society of Chemistry, 353 pp. https://doi.org/10.1039/9781849732901-00094

Sfara, V., Zerba, E. N. \& Alzogaray, R. A. (2006): Toxicity of pyrethroids and repellency of diethyltoluamide in two deltamethrin-resistant colonies of Triatoma infestans Klug, 1834 (Hemiptera: Reduviidae). - Memórias do Instituto Oswaldo Cruz 101: 89-94. https://doi.org/10.1590/S0074-02762006000100017

Sørensen, F. F., Bayley, M. \& BaAtrup, E. (1995): The effects of sublethal dimethoate exposure on the locomotor behaviour of the collembolan Folsomia candida (Isotomidae). - Environmental Toxicology and Chemistry 14: 1587-1590. https://doi.org/10.1002/ etc.5620140919

SzAвó, B. \& BAкоNYI, G. (2017): Multigenerational and transgenerational side-effects of an insecticide on eggs of Folsomia candida (Collembola). - Polish Journal of Ecology 65: 110-121. https://doi.org/10.3161/15052249PJE2017.65.1.010

Székács, I., Fejes, Á., Klátyik, S., Takács, E., Patkó, D., Pomóthy, J., Mörtl, M., Horváth, R., Madarász, E., Darvas, B. \& SzéKÁcs, A. (2014): Environmental and toxicological impacts of glyphosate with its formulating adjuvant. - International Journal of Biological, Veterinary, Agricultural and Food Engineering 8: 212-218.

Toews, M. D., Subramanyam, B. \& Rowan, J. M. (2003): Knockdown and mortality of adults of eight species of stored-product beetles exposed to four surfaces treated with spinosad. - Journal of Economic Entomology 96: 1967-1973. https://doi.org/10.1093/ jee/96.6.1967

Tooming, E., Merivee, E., Must, A., Sibul, I. \& Williams, I. (2014): Sub-lethal effects of the neurotoxic pyrethroid insecticide Fastac ${ }^{\circledR} 50 \mathrm{EC}$ on the general motor and locomotor activities of the non-targeted beneficial carabid beetle Platynus assimilis (Coleoptera: Carabidae). - Pest Management Science 70: 959-966. https://doi.org/10.1002/ps.3636

Tooming, E., Merivee, E., Must, A., Merivee, M. I., Sibul, I., Nurme, K. \& Williams, I. H. (2017): Behavioural effects of the neonicotinoid insecticide thiamethoxam on the predatory insect Platynus assimilis. - Ecotoxicology 26: 902-913. https:/doi. org/10.1007/s10646-017-1820-5

Tully, T., D’Haese, C. A., Richard, M. \& Ferriére, R. (2006): Two major evolutionary lineages revealed by molecular phylogeny in the parthenogenetic collembola species Folsomia candida. - Pedobiologia 50: 95-104. https://doi.org/10.1016/j.pedobi.2005.11.003

Vasquez, M. E., Holstege, D. M., \& TJeerdema, R. S. (2011): Aerobic versus anaerobic microbial degradation of etofenprox in a California rice field soil. - Journal of Agricultural and Food Chemistry 59: 2486-2492. https://doi.org/10.1021/jf1037773

Vatandoost, H., Ezeddinloo, L., Mahvi, A. H., Abai, M. R., Kia, E. B., \& Mobedi, I. (2004): Enhanced tolerance of house mosquito to different insecticides due to agricultural and household pesticides in sewage system of Tehran, Iran. - Iranian Journal of Environmental Health Science E Engineering 1: 42-45.

Verhoef, H. A. \& BrussaARd, L. (1990): Decomposition and nitrogen mineralization in natural and agroecosystems: the contribution of soil animals. - Biogeochemistry 11: 175-211. https://doi.org/10.1007/BF00004496

Weiner, M. L., Nemec, M., Sheets, L., Sargent, D. \& Breckenridge, C. (2009): Comparative functional observational battery study of twelve commercial pyrethroid insecticides in male rats following acute oral exposure. - Neurotoxicology 30: S1-S16. https://doi. org/10.1016/j.neuro.2009.08.014 
Westfall, P. H. (2014): Kurtosis as peakedness, 1905-2014. RIP. - The American Statistician 68: 191-195. https://doi.org/10.1080/00031305.2014.917055

WHO (2013): Guidelines for efficacy testing of spatial repellents. - World Health Organization, Press, Switzerland, $48 \mathrm{pp}$.

Zhang, X., LiU, J. \& FAN, Z. (2013): Stability of etofenprox in water emulsion induced by block copolymer and surfactant. - Colloids and Surfaces A: Physicochemical and Engineering Aspects 422: 191-198. https://doi.org/10.1016/j.colsurfa.2013.01.046

Yoshimoto, T., Ogawa, S., Udagawa, T. \& Numata, S. (1989): Development of a new insecticide, etofenprox. - Journal of Pesticide Science 14: 259-268. https://doi.org/10.1584/ jpestics.14.259

Received January 2, 2018, accepted July 19, 2018, published October 12, 2018 